\title{
High energy density capacitor based on the novel ammonium salt type ionic liquids and their mixing effect by propylene carbonate (PC)
}

\author{
Yong-Jung Kim*, Yutaka Matsuzawa*, Shinya Ozaki*, Ki Chul Park*, Chan Kim*, \\ Morinobu Endo ${ }^{* * *}$ \\ Hiroshi Yoshida ${ }^{\S}$, Gen Masuda ${ }^{\S}$, Takaya Sato ${ }^{\S}$, Mildred S. Dresselhaus ${ }^{\dagger}$
}

*Faculty of Engineering, Shinshu University, 4-17-1 Wakasato, Nagano, 380-8553, Japan

${ }^{\S}$ Nisshinbo Industries, Inc., 1-2-3, Ondai, Midori-ku, Chiba, 267-0056, Japan

${ }^{\dagger}$ Department of Physics and Department of Electrical Engineering and Computer Science, MIT, Cambridge, Massachusetts 02139, USA

**Corresponding author; Morinobu Endo Tel; +81-26-269-5201, Fax; +81-26-269-5208, e-mail; endo@endomoribu.shinshu-u.ac.jp 


\begin{abstract}
Novel ionic liquids comprised of a quaternary ammonium salt type cation have been applied to an electrolyte for high performance electric double-layer capacitors (EDLCs). The novel ionic liquids (IL-B; N, N-diethyl-N-methyl(2-methoxyethyl) ammonium tetrafluoroborate $\left(\mathrm{DEME}^{\left.-\mathrm{BF}_{4}\right)}\right.$ and IL-T; N, N-diethyl-N-methyl(2-methoxyethyl) ammonium bis(trifluoromethylsulfonyl)imide (DEME-TFSI)) are promising candidates for EDLC electrolytes in terms of a high decomposition voltage (wide voltage window) non-flammability, easy handling, non-volatility and low production costs. Notably, the wide voltage window indicates that IL-B and IL-T are more advantageous in energy density than a typical propylene carbonate-based electrolytes (i.e., TEA-BF $4 / \mathrm{PC}$ ) and a conventional imidazolium type ionic

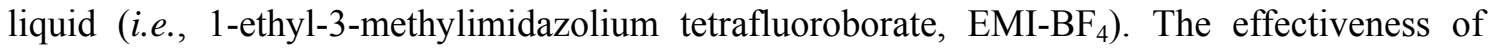
IL-B and IL-T on the application to EDLC electrolytes has been confirmed by using $\mathrm{KOH}$-activated mesophase pitch-based carbon fibers (MPCFs) as an electrode material. The combination of IL-T (IL-B) and KOH-activated MPCFs has provided $56 \mathrm{~F} / \mathrm{g}(51 \mathrm{~F} / \mathrm{g})$ of high specific capacitance at a maximum $\left(1 \mathrm{~mA} / \mathrm{cm}^{2}\right.$ discharge current density, $3.5 \mathrm{~V}$ charging voltage $)$, which is equivalent to $224 \mathrm{~F} / \mathrm{g}(204 \mathrm{~F} / \mathrm{g})$ in a conventional three-compartment measuring system. In addition, the specific capacitance of both ionic liquids has increased proportional to the increase in the applied voltage from 2.5 to $3.5 \mathrm{~V}$, in contrast to the decline observed for TEA-BF $4 / \mathrm{PC}$ at $3.5 \mathrm{~V}$. Furthermore, the mixture of the IL-B exhibiting high viscosity with propylene carbonate (1 M of IL-B in PC) has been found to provide an excellent capacitance behavior comparable to that observed for the pure IL-B. This indicates that the mixture has a great potential for application to EDLC electrolytes, similar to pure IL-B and IL-T.
\end{abstract}




\section{Introduction}

Ionic liquids (ILs) are organic salts with melting points under $100{ }^{\circ} \mathrm{C}$, which are often even lower than room temperature. Recently, the so-called room temperature molten salts (RTMSs) have been increasingly employed as substitutes for organic solvents traditionally used as chemical reaction media ${ }^{1-9}$. The most common RTMSs are imidazolium ${ }^{10}$ and pyridinium ${ }^{11}$ derivatives, and in addition, phosphonium ${ }^{12}$ or tetralkylammonium ${ }^{13}$ compounds can be also used for the same purpose. Aprotic solvents, such as propylene carbonate (PC), have been generally used as a solvent for electrochemical capacitors due to their higher decomposition voltage (i.e., a wider voltage window than those of aqueous electrolytes). A wide voltage window implies an enhancement of the energy density of single-cell capacitors, leading to the decrease in the number of cells required in a series stack. In this respect, we have adopted and investigated novel RTMSs with higher decomposition voltage as electrolytes for electrochemical double layer capacitors (EDLCs). Recent research has focused on the RTMSs containing imidazolium type cations (with various anions), such as 1-ethyl-3-methylimidazolium (EMI), because of their low viscosity, high ionic conductivity and low melting point ${ }^{14-23}$. However, its low cathodic stability is the most critical obstacle for the application to their practical use as an electrolyte.

Recently, Nisshinbo Industries, Inc. has synthesized novel ionic liquids with an ammonium salt type cation, which can be considered as a promising candidate for an electrolyte for EDLCs 24, 25 . In this work, the molecular structure of these two RTMSs has been confirmed using nuclear magnetic resonance (NMR) and infrared spectroscopy (IR) and elemental analysis (see Experimental). Furthermore, we report here the simulated ion size of the RTMSs and the capacitance response when they were used in combination with $\mathrm{KOH}$-activated mesophase pitch based carbon fibers (MPCFs) as electrode materials. Because of the problematic higher viscosity of Ionic liquid B, in addition, the mixing effect with PC in a fixed molar fraction has also been demonstrated. 


\section{Experimental}

\subsection{Materials for electrodes and electrolytes}

The MPCFs, graphitizable carbonaceous materials, were chosen as host materials for EDLC electrodes. After stabilization under an ambient atmosphere, carbonization was performed at $650{ }^{\circ} \mathrm{C}$. Then, the carbon fibers were milled mechanically to select a mean length of about 25 $\mu \mathrm{m}$. The selected carbon fibers were well mixed with potassium hydroxide $(\mathrm{KOH})$ as an activator. The mixture was heated to $700^{\circ} \mathrm{C}$ at a fixed programming rate in a nitrogen flow, and was held at $700^{\circ} \mathrm{C}$ for $2 \mathrm{~h}$. The obtained samples were washed with deionized distilled water to eliminate the excess $\mathrm{KOH}$, which was repeated until the washings reached $c a . \mathrm{pH}=7$. The mixing weight ratios of $\mathrm{KOH}$ to the host carbon material were varied from 1.5 to 4 . The sample definition was made by its resultant specific surface area. For example, ACF 2436 represents an activated carbon fiber with $2436 \mathrm{~m}^{2} / \mathrm{g}$ of BET (Brunauer-Emmett-Teller) area.

Two tetraalkylammonium type ILs, i.e., were used as electrolytes, which were supplied by Nisshinbo Industries. Inc. for the application to EDLCs, and they were designated as IL-B and IL-T, briefly. (IL-B: N, N-diethyl-N-methyl(2-methoxyethyl)ammonium tetrafluoroborate (DEME-BF 4 and IL-T: N, N-diethyl-N-methyl(2-methoxyethyl)ammonium bis(trifluoromethylsulfonyl)imide $\left(\right.$ DEME-TFSI, TFSI $\left.=\left(\mathrm{CF}_{3} \mathrm{SO}_{2}\right)_{2} \mathrm{~N}\right)$. These ILs consist of the same cation structure with eight carbon atoms, but possess the different anions of $\mathrm{BF}_{4}$ and TFSI. The fundamental properties for these two ILs are summarized in Table 1. The synthesis process of these two ILs has been reported in a previous paper and patent ${ }^{24,25}$. In this work, the structures of IL-B and IL-T were confirmed using ${ }^{1} \mathrm{H},{ }^{13} \mathrm{C}$ NMR spectroscopy (JNM-GX400, JEOL), infrared spectroscopy (Perkin Elmer, 1600-series FT-IR) and elemental analysis (Flash EA 1112series, CE Instruments). The ${ }^{1} \mathrm{H}$ and ${ }^{13} \mathrm{C}$ chemical shifts $(\delta)$ are reported in ppm, downfield from the internal tetramethylsilane (TMS). Spectral assignments were made with the aid of DEPT (distortionless enhancement by polarization transfer), using ${ }^{1} \mathrm{H}-{ }^{1} \mathrm{H}$ COSY 
(correlated spectroscopy), and ${ }^{1} \mathrm{H}-{ }^{13} \mathrm{C}$ COSY techniques.

A typical electrolyte for EDLCs, i.e., $1 \mathrm{M}$ of tetraethyleneammonium tetrafluoroborate TEA-BF 4 (Tomiyama pure chemical industries Ltd., D. C. grade) in propylene carbonate (PC) was used as a standard in order to appreciate the results obtained by using IL-B and IL-T as electrolytes. Furthermore, the mixture of a 1 molar fraction of IL-B to PC solvent was also investigated due to the problematic high viscosity of IL-B.

\section{Assignment information}

Ionic liquid B

${ }^{1} \mathrm{H}$ NMR $\left(400 \mathrm{MHz}, \mathrm{CDCl}_{3}\right): \delta=1.36\left(\mathrm{t}, 2 \times 3 \mathrm{H}, J=7.2 \mathrm{~Hz}, \mathrm{CH}_{2} \mathrm{CH}_{3}\right), 3.05\left(\mathrm{~s}, 3 \mathrm{H}, \mathrm{CH}_{3} \mathrm{~N}^{+}\right), 3.34$ (s, $3 \mathrm{H}, \mathrm{OCH}_{3}$ ), 3.44 (quart., $2 \times 2 \mathrm{H}, J=7.2 \mathrm{~Hz}, \mathrm{CH}_{2} \mathrm{CH}_{3}$ ), 3.49-3.52(m, $2 \mathrm{H}, \mathrm{CH}_{2} \mathrm{CH}_{2} \mathrm{~N}^{+}$), 3.78-3.81 (m, $\left.2 \mathrm{H}, \mathrm{CH}_{2} \mathrm{CH}_{2} \mathrm{~N}^{+}\right),{ }^{13} \mathrm{C}$ NMR $\left(100 \mathrm{MHz}, \mathrm{CDCl}_{3}\right): \delta=7.9\left(\mathrm{CH}_{2} \mathrm{CH}_{3}\right), 47.6\left(\mathrm{CH}_{3} \mathrm{~N}^{+}\right)$, $57.4\left(\mathrm{CH}_{2} \mathrm{CH}_{3}\right), 58.9\left(\mathrm{OCH}_{3}\right), 60.0\left(\mathrm{CH}_{2} \mathrm{CH}_{2} \mathrm{~N}^{+}\right), 65.7\left(\mathrm{CH}_{2} \mathrm{CH}_{2} \mathrm{~N}^{+}\right)$.

IR (neat): $v($ or $\delta)=2996,2952,2920$, and 2828 (m, C-H str.), 1466 (m, C-H sym. deform. of $\left.\mathrm{OCH}_{3}\right), 1402,1286$, and 1056 (m-s, C-H deform. and C-O str.).

Anal. Calcd for $\mathrm{C}_{8} \mathrm{H}_{20} \mathrm{NOBF}_{4}$ : C, 41.23; H, 8.65; N, 6.01. Found: C, 38.77; H, 8.09; N, 8.39.

Ionic liquid $T$

${ }^{1} \mathrm{H}$ NMR $\left(400 \mathrm{MHz}, \mathrm{CDCl}_{3}\right): \delta=1.35\left(\mathrm{t}, 2 \times 3 \mathrm{H}, J=7.1 \mathrm{~Hz}, \mathrm{CH}_{2} \mathrm{CH}_{3}\right), 3.01\left(\mathrm{~s}, 3 \mathrm{H}, \mathrm{CH}_{3} \mathrm{~N}^{+}\right)$, 3.37-3.47 (base-line unresolved s, quart., and m, 9H, $\mathrm{OCH}_{3}, \mathrm{CH}_{2} \mathrm{CH}_{3}, \mathrm{CH}_{2} \mathrm{CH}_{2} \mathrm{~N}^{+}$), 3.75 (app. br. s, $\left.2 \mathrm{H}, \mathrm{CH}_{2} \mathrm{CH}_{2} \mathrm{~N}^{+}\right),{ }^{13} \mathrm{C}$ NMR $\left(100 \mathrm{MHz}, \mathrm{CDCl}_{3}\right): \delta=7.8\left(\mathrm{CH}_{2} \mathrm{CH}_{3}\right), 47.9\left(\mathrm{CH}_{3} \mathrm{~N}^{+}\right), 57.7$ $\left(\mathrm{CH}_{2} \mathrm{CH}_{3}\right), 59.0\left(\mathrm{OCH}_{3}\right), 60.2\left(\mathrm{CH}_{2} \mathrm{CH}_{2} \mathrm{~N}^{+}\right), 65.6\left(\mathrm{CH}_{2} \mathrm{CH}_{2} \mathrm{~N}^{+}\right)$.

IR (neat): $v($ or $\delta)=2998,2946,2904$, and 2832 (m, C-H str.), 1464 (m, C-H sym. deform. of $\left.\mathrm{OCH}_{3}\right), 1354,1196,1140,1058$ (s, C-H deform. and C-O str.).

Anal. Calcd for $\mathrm{C}_{10} \mathrm{H}_{20} \mathrm{~N}_{2} \mathrm{O}_{5} \mathrm{~S}_{2} \mathrm{~F}_{6}: \mathrm{C}, 28.17 ; \mathrm{H}, 4.73 ; \mathrm{N}, 6.57 ; \mathrm{S}, 15.04$. Found: C, 28.16; H, 4.19; N, 7.22; S, 13.54 . 


\subsection{Electrochemical measurements}

In order to measure the capacitance, a coin type electrode was made around $0.3 \mathrm{~mm}$ in thickness by using 5 wt.\% of poly-tetrafluoroethylene (PTFE, Daikin Industries) as a binder, and a glassy carbon plate was used as a current collector. The capacitor was constructed by a couple of electrodes face to face, with a separator (glass filter paper, Oribest Co. Ltd.) inserted between these electrodes. As described above, $1 \mathrm{M}$ of $\mathrm{TEA}-\mathrm{BF} / \mathrm{PC}$ was used as a standard for comparison with IL-B and IL-T. Charging was performed at a constant current of $5 \mathrm{~mA} / \mathrm{cm}^{2}$ and charge-discharge cycles were performed at various current densities. The capacitance was calculated from the corresponding voltage variation of the discharge at various discharge current densities in the 1 to $60 \mathrm{~mA} / \mathrm{cm}^{2}$ range. For cyclic voltammograms (HZ-3000, Hokuto Denko) the scan rate was fixed at $1 \mathrm{mVs}^{-1}$, and the galvanostatic charge/discharge characteristics were measured in the voltage range from $0-4 \mathrm{~V}$ and these data were used to characterize the electrochemical behavior.

A conventional three-compartment cell has also been used to confirm the decomposition voltage window of each electrolyte system. The resultant voltammograms were obtained using a Pt disk as both a working electrode and a counter electrode. In order to avoid the unnecessary junction potential, the ferrocene/ferricinium $\left(\mathrm{Fc} / \mathrm{Fc}^{+}\right)$electrode ${ }^{26}$ was used as a reference electrode with a potential sweep rate of $1 \mathrm{mVs}^{-1}$ using a HZ-3000 instrument. The viscosity was measured using a programmable viscometer (RVDV-III, Brookfield, spindle: CP-40).

\section{Results and discussion}

\subsection{Characterization of electrode materials using high-resolution gas adsorption}

Figure 1 shows high-resolution $\mathrm{N}_{2}$ adsorption-desorption isotherms of the activated carbon fibers for electrodes using an ASAP 2010 instrument (Micromeritics). The sample identification was made by the BET surface areas, which were determined by the multi-point BET method. The abscissas of Fig. 1 are expressed by a linear (a) and a logarithmic scale (b) of the relative 
pressure $\left(\mathrm{P} / \mathrm{P}_{0}\right)$. All samples basically followed the type I behavior with no hysteresis. However, the type of isotherm gradually approached a type showing the presence of small mesopores. The angle of the round knee between the steep initial rise and the plateau was relieved as the $\mathrm{KOH}$ addition increased from ACF 510 to ACF 2436. In addition, the plateau exhibited the shape of a gradual increase along the pressure axis. These results imply a variation of the pore size distribution, meaning that wider micropores were induced as the $\mathrm{KOH}$ addition increased. In order to elucidate the micropore structure of the samples, the adsorption data in an extremely low region of relative pressure $\mathrm{P} / \mathrm{P}_{0}$ should be considered in detail. Figure. $1(\mathrm{~b})$ presents the details of the adsorption behavior in the low relative pressure, clearly showing that the beginning point of $\mathrm{N}_{2}$ adsorption is in the vicinity of $\mathrm{P} / \mathrm{P}_{0}=10^{-6}$. The ACF 2436 exhibited the maximum amount of adsorption among the four samples, whereas the adsorption behavior in the quite low region of $\mathrm{P} / \mathrm{P}_{0}$ showed no large difference compared with those of other samples. The observed adsorption behavior could be attributed to the correlation between larger pore diameter and the size of gas probe molecules. The details of the results obtained from nitrogen adsorption are summarized in Table 2.

Figure 2 represents the pore size distribution obtained by two methods, i.e., (a) the Barrett-Joyner-Halenda (BJH) and (b) Dubinin-Astakhov (DA) methods. The results indicated a large difference in pore structures between the ACF 2436 and other samples. The ACF 510, ACF 817 and ACF 1143 had a microporous dominant pore structure. However, the ACF 2436 involved not only micropores but also small mesopores to exhibit a wider pore size distribution than those of other samples. The pore size in the maximum pore volume existed in the micropore regime, which was also shifted to the larger size.

Figure 3 shows the variation of the apparent density of electrodes as a function of the $\mathrm{KOH}$ addition made for activation. In order to reduce the deviations introduced by manipulation, the values were obtained from the average of three of the five measured values, by removing the maximum and minimum values. The apparent densities should be distinguished from the 
intrinsic density inherited from the homogeneous phase of the samples, because each sample contains the effect by the binder addition. The apparent densities decreased linearly from ca. 0.9 to $0.4 \mathrm{~g} / \mathrm{cm}^{3}$ as the amount of $\mathrm{KOH}$ addition increased from $150 \mathrm{wt} . \%$ to $400 \mathrm{wt} . \%$. These values should be considered as an important factor, because it has an effect on the calculation of the volumetric capacitance.

\subsection{Characterization for the novel ionic liquids used in this study}

Figure 4 represents the average diameter of the ion molecules of IL-B and -T, which were obtained from a computer simulation. The force fields of the model for the IL-B and -T were taken to be a Lennard-Jones potential integrated over the whole feature using a van der Waals surface. Solvent effects need not be taken into account in calculating their ionic radii, because these RTMSs are comprised of only ions, containing no solvent. Both of the IL-B and IL-T consist of the same DEME cation with eight carbon atoms (Fig. 4(a)), while each of them has a different anion, i.e., the TFSI anion for IL-T $\left(\left(\mathrm{CF}_{3} \mathrm{SO}_{2}\right)_{2} \mathrm{~N}^{-}\right.$, Fig. 4(b)) and the tetrafluoroborate anion for IL-B $\left(\mathrm{BF}_{4}^{-}\right.$, Fig. 4(c)). The average diameters calculated in this work were 0.754 (DEME cation), 0.721 (TFSI anion) and $0.439 \mathrm{~nm}\left(\mathrm{BF}_{4}^{-}\right.$anion). For reference, the ionic radii of the above-mentioned typical electrolyte TEA-BF $4 / \mathrm{PC}$ have been previously reported to be 0.74 $\mathrm{nm}$ for the cation and $0.43 \mathrm{~nm}$ for the anion ${ }^{27-29}$.

Figure 5 represents the cyclic-voltammograms of IL-B and IL-T (tetraalkylammonium salt

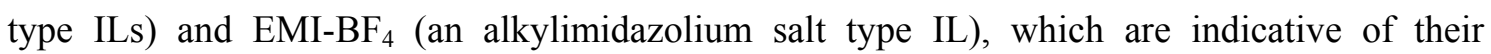
electrochemical stability. The sweep rate for the voltammetry was fixed at $1 \mathrm{mVs}^{-1}$. The decomposition voltages clearly indicate that IL-B and IL-T have a wider operating voltage window than that of EMI-BF 4 . The values obtained between the anodic $\left(E_{\text {red }}\right)$ and the cathodic $\left(E_{o x}\right)$ decomposition voltages were $-3.6 \mathrm{~V} /+2.3 \mathrm{~V}(5.9 \mathrm{~V}$, based on the set point of decomposition) for IL-B, -3.3 V/+2.2 V (5.5 V) for IL-T and -2.2 V/1.9 V (4.1 V) for EMI-BF 4 . These results demonstrate that tetraalkylammonium cation is highly stable in the applied voltage 
window, compared with the alkylimidazolium cation of the conventional EMI-BF 4. It is therefore concluded that the IL-B and IL-T have a potential applicability to high energy density devices such as EDLCs. Although comprised of the same cation, IL-B and IL-T exhibit quite different physicochemical properties. As shown in Table 1, IL-B has clear melting and freezing points, whereas IL-T has no corresponding definite points. However, it should be noticed that IL-T has a glass transition point at $-91^{\circ} \mathrm{C}$, keeping a liquid state up to the transition point. This would be expected to enhance the performance of EDLCs even under the harsh condition of quite low temperature. As regards viscosity, furthermore, IL-B exhibits 4.6 times as high a value as that of IL-T (560 mPa.s for IL-B and $120 \mathrm{mPa} \cdot \mathrm{s}$ for IL-T at 293K). As just described, the physicochemical properties of ILs are sensitively dependent on the both ion species of both the cations and anions.

\subsection{Electrochemical properties using a symmetric configuration}

\subsubsection{Comparison of double-layer capacitance behaviors on IL-B, $T$ and TEA-BF $/ P C$}

Figure 6 represents the variations of the specific capacitance per (a) unit weight (F/g), (b) unit volume and (c) unit area using the $\mathrm{KOH}$-activated MPCFs as electrode materials. The charge cycles were carried out up to $3.5 \mathrm{~V}$ at a constant current of $5 \mathrm{~mA} / \mathrm{cm}^{2}$, and the discharge cycle was performed at $1 \mathrm{~mA} / \mathrm{cm}^{2}$. All samples showed an increase in the gravimetric capacitance $(\mathrm{F} / \mathrm{g})$ as the $\mathrm{KOH}$ addition increased. At the sample with the low $\mathrm{KOH}$ addition (below 200 wt. \%), the typical TEA-BF $4 / \mathrm{PC}$ electrolyte showed the best capacitance among the samples. As the $\mathrm{KOH}$ addition increased, however, their order was partly interchanged, and furthermore, completely reversed at 400 wt. $\%$ of the $\mathrm{KOH}$ addition. This clearly indicates that both the cation and anion of ILs largely affect the capacitance uptake. Furthermore, the smaller capacitance uptake of IL-B than that of IL-T implies that it is caused by the smaller anion size of IL-B (that is, it is too small to stably form an electric double layer) than that of IL-T. Therefore, the increment of the capacitance uptake of IL-B and -T would be attributable to the 
correlation between the pore size of the $\mathrm{KOH}$-activated MPCFs and the ionic radii of the cation and anion.

Figure 7 represents the effect of the charging voltage on the capacitance uptake using IL-B, IL-T and 1 molar fraction of TEA-BF 4 in PC. Figures. 7(a) and (b) represent the variation of gravimetric capacitance (F/g) obtained at $1 \mathrm{~mA} / \mathrm{cm}^{2}$ and $10 \mathrm{~mA} / \mathrm{cm}^{2}$ of discharge current density, respectively. As seen in Fig. 7(a), the capacitance obtained by IL-B and IL-T continuously increased as a function of the applied voltage (although it was limited up to $3.5 \mathrm{~V}$ ). In contrast, the typical electrolyte TEA-BF $4 / \mathrm{PC}$ shows a decrease at the $3.5 \mathrm{~V}$ charge, which is attributable to the decomposition of the PC solvent. These results imply that IL-B and IL-T are quite effective for acquiring a high energy density, as far as $1 \mathrm{~mA} / \mathrm{cm}^{2}$ of the low discharge current density is concerned. In Fig. 7(b), IL-B characteristically showed a drastically lower capacitance. This would be attributed to the quite high viscosity $(560 \mathrm{mPa} \cdot \mathrm{s}$ at $293 \mathrm{~K})$ of IL-B, which is considered to largely affect the ionic mobility in the system. For reference, the viscosity of PC has been previously reported to be $0.25 \mathrm{mPa} \cdot \mathrm{s}$ at $298 \mathrm{~K}$ by Makoto Ue et al. ${ }^{30}$. In both cases of 1 and 10 $\mathrm{mA} / \mathrm{cm}^{2}$ of the discharge current densities, the capacitance of IL-B and IL-T decreased with a increase in the viscosity. However, it is more significant that the capacitance of IL-B and IL-T have continuously increased as a function of charging voltage, different from the typical electrolyte system $\mathrm{TEA}_{-}-\mathrm{BF}_{4} / \mathrm{PC}$. In order to overcome the obstacle caused by the high viscosity of IL-B and make it applicable to EDLCs, we have attempted to mix IL-B with PC (see the next section).

3.3.2 Resistance enhancement of the $I L-B$ by mixing with $P C$ and the evaluation of its capacitance properties

Figure 8 shows the variation of the viscosity of the IL-B/PC mixtures as a function of weight fractions. The measurements were performed using a programmable viscometer (RVDV-III, Brookfield, U.S.A; spindle: CP-40) at $303 \mathrm{~K}$ under highly dried conditions due to 
the hygroscopic property of the mixtures. Generally, the viscosity of ILs is sensitive to the humidity present in the atmosphere. In fact, the measured values of the viscosity of IL-B varied from 360 to $316 \mathrm{mPa} \cdot \mathrm{s}$, depending on the atmospheric humidity. Hence, we have kept the water content below $30 \mathrm{ppm}$ for all measurements. The filled circle in the figure indicates the data obtained from $1 \mathrm{M}$ (w/w ratio: $19.5 \%$, w/w: weight/weight) of IL-B in PC. It has been found that the viscosity of the mixture takes similar values up to the $50 \%$ addition of IL-B, and increases exponentially beyond the $58.7 \%$ addition ( $3 \mathrm{M}$ of IL-B in PC). Based on this, we have chosen the 1 molar fraction of IL-B/PC mixture in order to enhance the resistance. With respect to consideration for the practical use, a good equivalent series resistance (ESR) is indispensable.

Figure 9 represents the mixing effect of IL-B with PC on the capacitance uptake. Each graph shows the variation of the specific capacitance per (a) unit weight $(\mathrm{F} / \mathrm{g})$, (b) unit volume and (c) unit area for the $\mathrm{KOH}$-activated MPCFs as electrode materials. The charge cycle was limited to $2.5 \mathrm{~V}$ at a constant current of $5 \mathrm{~mA} / \mathrm{cm}^{2}$ to prevent the decomposition of $\mathrm{PC}$, and the discharge cycle was performed at a current density of $1 \mathrm{~mA} / \mathrm{cm}^{2}$. As described above, the high viscosity of IL-B prevents ion migration in the dispersive regime, which makes it difficult to apply it to EDLCs. In view of its practical application to EDLCs, the high viscosity would become a fatal drawback for high-speed charge/discharge operation. In this work, therefore, the attempt to mix IL-B with PC was made to reduce the viscosity of IL-B. In fact, the viscosity of the IL-B/PC mixture (at $1 \mathrm{M}$ fraction) has abruptly decreased to $c a .0 .4 \%$ of the viscosity of pure IL-B, as is shown in Fig. 8. The mixing effect is reflected in the capacitance results (Fig. 9). Evidently, the mixing of IL-B and PC has enhanced the capacitance uptake (at a current density of $1 \mathrm{~mA} / \mathrm{cm}^{2}$ ). Furthermore, it is interesting to note that the IL-B/PC mixture is totally superior to TEA-BF $4 /$ PC. The effectiveness of each ion can be described by Fig. 9(c). It is desirable to now apply this material to a small size of a high performance capacitor making a restricted space application possible. 
Figure 10 shows the dynamic equivalent series resistance (DESR) obtained at various current densities under discharge conditions, where three distinct values of charging voltages were adopted to confirm the electrochemical stability: (a) $2.5 \mathrm{~V}$, (b) $3.0 \mathrm{~V}$ and (c) $3.5 \mathrm{~V}$. The data points were calculated from the IR drops under direct current conditions. In the case of the charging at $2.5 \mathrm{~V}$, each electrolyte exhibited a stable behavior to take a nearly constant value of resistance at every current density for discharge (Fig. 10(a)). It is noteworthy that the resistance of IL-B was much higher than that of the IL-B/PC mixture, resulting in about a four-fold increase in capacitance. As seen in Fig. 10, (b) and (c), the electrochemical behavior of the PC mixtures became unstable with the increase of the applied voltage in the charging process, whereas pure IL-B was independent of the applied voltage. This clearly demonstrates that the PC dominant mixtures are largely dependent on the electrochemical properties of PC.

\section{Conclusion}

The specific capacitance of the EDLC consisting of the quaternary ammonium salt type ILs and $\mathrm{KOH}$-activated MPCFs has exhibited i) higher values of specific capacitance than that observed for the typical electrolyte TEA-BF $4 / \mathrm{PC}$ (i.e., TEA-BF $4 / \mathrm{PC}: 42 \mathrm{~F} / \mathrm{g}$, IL-T: $56 \mathrm{~F} / \mathrm{g}$ and IL-B: $51 \mathrm{~F} / \mathrm{g}$ at $1 \mathrm{~mA} / \mathrm{cm}^{2}$ discharge current density and at $3.5 \mathrm{~V}$ charging voltage), and ii) the capacitance increased proportional to the increase in the applied voltage from 2.5 to $3.5 \mathrm{~V}$ (largely different from the decline observed for TEA-BF $4 / \mathrm{PC}$ at $3.5 \mathrm{~V}$ ). Furthermore, it has been found that the mixture of the IL-B exhibiting high viscosity with propylene carbonate (1 M of IL-B in PC) brings about an excellent capacitance behavior, comparable to that observed for the pure IL-B. These results demonstrate that there are two kinds of ionic liquids with an ammonium salt type that are applicable to high performance EDLCs as an alternative to conventional PC-based electrolytes. The ILs have a variety of special properties: good solvents for both organics and inorganics, they are liquid over a wide range of temperature, they are not volatile, and are highly thermally stable, non-flammable, and less toxic than usual organic 
solvents. That is, ILs are very environmentally friendly. Furthermore, excellent capacitor properties in terms of the energy density have been demonstrated in this report. The appropriate modification of ILs and the choice of proper electrode materials may find applications in future energy devices free from environmental problems as well as ILs have good energy density performance.

\section{Acknowledgements}

This work was supported by the CLUSTER of Ministry of Education, Culture, Sports, Science and Technology, and Morinobu Endo and Yong Jung Kim (Shinshu University) greatly acknowledges the support.

\section{References}

1. K. S. Kim, S. J. Choi, D. Demberelnyamba, H. Lee, J. S. Oh, B. B. Lee, Chem Comm. 7, 828 (2004)

2. Y. Zhou, J. H. Schattka, M. Antonietti, Nanoletters, 4, 477 (2004)

3. D. W. Kim, D. Y. Chi, Angew. Chem. Int. Ed. 43, 483 (2004)

4. Paulo A. Z. Suarez, Vânia M. Selbach, Jeane E. L. Dullius, Sandra Einloft, Clarisse M. S. Piatnicki, Denise S. Azambuja, Roberto F. de Souza and Jairton Dupont, Electrochimica Acta, 42, $2533(1997)$

5. H. Matsumoto, H. Kageyama, Y. Miyazaki, Chem. Comm. 16, 1726 (2002)

6. John D. Stenger-Smith, Cynthia K. Webber, N. Anderson, Andrew P. Chanfin, K. Zong, John R. Reynolds, J. Electrochem. Soc. 149, A 973 (2002)

7. Alan B. McEwen, Helen L. Ngo, K. LeCompte, Jay L. Goldman, J. Electrochem. Soc. 146, $1687(1999)$

8. Y. S. Hu, H. Li, X. Huang, L. Chen, Electrochem. Comm. 6, 28 (2004)

9. J. N. Barisci, G. G. Wallace, D. R. MacFarlane, R. H. Baughman, Electrochem. Comm. 6, 22 
(2004)

10. L. A. Blanchard, D. Hancu, E. J. Beckman, J. F. Brennecke, Nature 399, 28 (1999)

11. H. L. Chum, R. A. Osteryoung, in: D. Inman, D. Lovering, editor, Ionic Liquids, New York: Plenum Press (1981)

12. C. J. Bradaric, A. Downard, C. Kennedy, A. J. Robertson, Y. Zhou, Green Chem., 5, 143 (2003)

13. J. Sun, M. Forsyth, D. R. MacFarlane, J. Phys. Chem. B 102, 8858 (1998)

14. R. Hagiwara, Y. Ito, J. of Fluorine Chem. 105, 221 (2000)

15. V. R. Koch, C. Nanjundiah, and J. L. Goldman, in: Proceedings of the $5^{\text {th }}$ International Seminar on Double Layer Capacitors and Similar Energy Storage Devices, Florida Educational Seminars, (1995).

16. V. R. Koch, C. Nanjundiah, and R. T. Carlin, U. S. Patent, 5, 827, 602 (1998).

17. M. Ue and M. Takeda, Electrochemistry, 70, 194 (2002).

18. M. Ue and M. Takeda, J. Korean Electrochem. Soc., 5, 192 (2002).

19. M. Ue, M. Takeda, T. Takahashi, and M. Takehara, Electrochem. Solid-State Lett., 5, A119 (2002).

20. M. Ue, M. Takeda, A. Toriumi, A. Kominato, R. Hagiwara, and Y. Ito, J. Electrochem. Soc., 150, A499 (2003).

21. T. Sato, Material Stage, 4, 73 (2003).

22. M. Ue, "Ionic Liquids" (Ed. H. Ohno), CMC, Tokyo, 232 (2003).

23. Z.-B. Zhou, M. Takeda, and M. Ue, J. Fluorine Chem., 125, 471 (2004).

24. T. Sato, G.. Masuda, K. Takagi, Electrochimica Acta. 49, 3603 (2004)

25. T. Sato, G.. Masuda, R. Nodu, International Patent WO02/076924 A1 (2002)

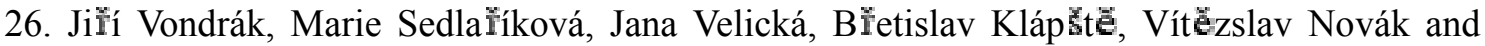
Jakub Reiter, Gel polymer electrolytes based on PMMA: III. PMMA gels containing cadmium, Electrochimica Acta, 48(8), 1001-1004 (2003) 
27. M. Endo, Y. J. Kim, H. Ohta, K. Ishii, T. Inoue, M. S. Dresselhaus, Y. Nishimura, T. Maeda, Carbon 40, 2613 (2002)

28. M. Ue, J. Electrochem. Soc., 141, 3336 (1994)

29. M. Ue, A. Murakami, and S. Nakamura, J. Electrochem. Soc., 149, A1385 (2002)

30. M. Ue, S. Mori, J. Electrochem. Soc. 142, 2577 (1995) 


\section{Figure captions}

Figure 1. High-resolution $\mathrm{N}_{2}$ adsorption-desorption isotherms of activated carbon fibers used for electrodes. The sample definition is made by its BET surface areas, which was determined by the multi-point Brunauer-Emmett-Teller (BET) method. Here, the abscissas are expressed by a linear (a) and logarithmic (b) dependence of the relative pressure $\left(\mathrm{P} / \mathrm{P}_{0}\right)$.

Figure 2. The pore size distribution obtained by two methods; (a) Barrett-Joyner-Halenda (BJH) and (b) Dubinin-Astakhov (DA) for various activated carbon fiber samples.

Figure 3. Variation of the apparent density of the electrodes as a function of the $\mathrm{KOH}$ amount added for activation

Figure 4. Simulation results for possible ion sizes, describing both the anions and cations of the ILs that control the kinetics of charge transfer shown in relation to the electrode's pore size.; A. D. $=$ Average diameter.

Figure 5. Electrochemical stability of two ammonium salt type ILs and an EMI type IL using cyclic-voltammograms. The sweep rate for the voltammetry was fixed at $1 \mathrm{mVs}^{-1}$.

Figure 6. Variations of the specific capacitance per (a) unit weight (F/g), (b) unit volume and (c) unit area using MPCF-based activated carbon as an electrode material which is activated using $\mathrm{KOH}$ addition.

Figure 7. Effect of the charging voltage on the capacitance uptake using IL-B, IL-T and conventional TEA-BF 4 in $\mathrm{PC}$ with 0.8 and 1 molar fraction; (a) and (b) represent the variation of 
the gravimetric $(\mathrm{F} / \mathrm{g})$ capacitance obtained at $1 \mathrm{~mA} / \mathrm{cm}^{2}$ and $10 \mathrm{~mA} / \mathrm{cm}^{2}$ discharge current density using ACF 2436 as an electrode material, respectively.

Figure 8. Variation of the viscosity for the IL-B mixture as a function of the IL weight fraction. The measurements were performed at $303 \mathrm{~K}$ under highly dried conditions due to the hygroscopic nature of ILs.

Figure 9. Mixing effect of the IL-B with PC on the capacitance uptake; the specific capacitance per (a) unit weight (F/g), (b) unit volume and (c) unit area using MPCF-based activated carbon fibers as an electrode material that was activated using varying amounts of $\mathrm{KOH}$ addition.

Figure 10. Dynamic equivalent series resistance (DESR) obtained for various samples at each current density for discharge. Each point was calculated from the IR drop under direct current (dc) conditions. In addition, the electrochemical stability for various charging voltages has also been confirmed; (a) $2.5 \mathrm{~V}$, (b) $3.0 \mathrm{~V}$ and (c) $3.5 \mathrm{~V}$.

\section{Table captions}

Table 1. Physicochemical properties for the two ILs used in this study are summarized.

Table 2. Results obtained from Nitrogen adsorption of materials used as electrodes are summarized. 
Table 1. Fundamental properties of the ILs used in this study

\begin{tabular}{|c|c|c|}
\hline Properties & IL-B & IL-T \\
\hline Structure & $\begin{array}{l}\mathrm{CH}_{3}-\mathrm{CH}_{2} \backslash \mathrm{N}^{+}-\mathrm{CH}_{2}-\mathrm{CH}_{2}-\mathrm{OCH}_{3} \\
\mathrm{CH}_{3}-\mathrm{CH}_{2}-\mathrm{BF}_{4}\end{array}$ & $\begin{array}{l}\mathrm{CH}_{3}-\mathrm{CH}_{2} \\
\mathrm{CH}_{3}-\mathrm{CH}_{2}-\mathrm{N}^{+}-\mathrm{CH}_{\mathrm{CH}_{3}}-\mathrm{CH}_{2}-\mathrm{OCH}_{3}\end{array} \underbrace{-\mathrm{SO}_{2}-\mathrm{CF}_{3}}_{\mathrm{NO}_{2}-\mathrm{CF}_{3}}$ \\
\hline Molecular weight & 233.1 & 426.4 \\
\hline Specific gravity & 1.17 & 1.24 \\
\hline $\begin{array}{l}\text { Potential window } \\
(\mathrm{V} \text { vs. } \mathrm{Ag} / \mathrm{AgCl})\end{array}$ & $-3.0 /+3.0$ & $-3.0 /+2.7$ \\
\hline $\begin{array}{c}\text { Viscosity } \\
\left(\mathrm{mPa} \cdot \mathrm{s}, 20^{\circ} \mathrm{C}\right)\end{array}$ & 560 & 120 \\
\hline Melting point $\left({ }^{\circ} \mathrm{C}\right)$ & 9 & - \\
\hline Freezing point $\left({ }^{\circ} \mathrm{C}\right)$ & -35 & - \\
\hline
\end{tabular}


Table 2. The results obtained from nitrogen adsorption at $77 \mathrm{~K}$.

\begin{tabular}{|c|c|c|c|c|c|}
\hline Sample ID & $\begin{array}{c}\text { KOH } \\
\text { addition }\end{array}$ & TPV & MPV & APD & Microporosity \\
\hline ACF 510 & 150 & 0.26 & 0.21 & 20.73 & 79.61 \\
\hline ACF 817 & 200 & 0.42 & 0.34 & 20.39 & 80.60 \\
\hline ACF 1143 & 250 & 0.58 & 0.46 & 20.27 & 78.54 \\
\hline ACF 2436 & 400 & 1.38 & 0.41 & 21.78 & 29.76 \\
\hline
\end{tabular}

1) Wt. \% (=KOH/sample), 2) TPV; Total pore volume $\left(\mathrm{cm}^{3} / \mathrm{g}\right)$ at the relative pressure of 0.9907 , $\left.\mathrm{cm}^{3} / \mathrm{g}, 3\right)$ Micropore volume $\left.\mathrm{cm}^{3} / \mathrm{g}, 4\right)$ Average pore diameter $(\AA)$,

5) $=\mathrm{MPV} / \mathrm{TPV} \times 100$ 